inspiration, \&c. A positive result in health can be discounted.

5. A negative result can be relied upon if the patient is ill except in cases of very acute tubercle, when a positive result ensues later.

Fluctuation of the reaction.-In very acute tubercle the antibody cannot be detected; Dr. d'Este Emery also found this. In less acute it is present in a proportion of 1 to 4 compared with alexin; as the case progresses the proportion gradually increases to equal parts-i.e., 10 c.mm. of antigen will fix the complement in $10 \mathrm{c} . \mathrm{mm}$. of fresh serum without the addition of any heated serum. As the case improves the antibodies pass off, till finally they can only be demonstrated by exercising the diseased organ or structure, or after subjecting it to passive congestion, or lighting it up by an injection of old tuberculin or peptone broth.

These latter measures give one a simple plan of further testing a case suspected to be tubercle, but giving a negative reaction.

As the first six months of this work was done in the inoculation laboratory at St. Mary's Hospital, London, W., most of the cases being Sir Almroth Wright's, I had, thanks to the kindness of Sir Almroth Wright, ample opportunity of comparing the two methods. My antigen and the tubercle emulsion used in the opsonic test are, except for the degree of dilution, the same; hence they must react on the same antibody.

I found that a low opsonic index went with a high immunity index, and vice versâ. This forces one to the conclusion that thermolabile opsonin is complement, and that the variations in the opsonic index are due to the absorption of complement during the incubation of the opsonic capillary tubes -i.e., the more the antibody present, the more the thermolabile opsonin absorbed. This is a very important consideration in treatment, for a lowering of the opsonic index should be the aim and not the dread. It further makes one reconsider the whole principle of the opsonic theory. I look upon a phagocytic index as only another means of demon. strating the Bordet-Gengou reaction.

As regards treatment by tuberculin, this test gives a laboratory demonstration of the poor value of tuberculin. Tuberculin is not an antigen to the true tubercle antibody; why, then, use it? In these days of autogenous vaccines $I$ cannot understand why tuberculin has not long ago been discarded; I am inclined to think the reason is because it is a foreign introduction. I have found freshly prepared tubercle emulsion given in the same doses as tuberculin to be much more effective, but at present $I$ am not in a position to state the case fully.-I am, Sir, yours faithfully,

V. B. NESFIELD, F.R.C.S. Eng.,

Major, I.M.S. ; late Chemical Examiner and Bacteriologist, Government United Provinces, India.

Almora, U.P., Sept. 23rd, 1914.

\section{THE LONDON PANEL COMMITTEE AND THE PRESCRIBING OF PANEL DOCTORS.} To the Editor of THE LANCET.

SIR,-I have received a notice from the secretary of the London Panel Committee that they are, at the request of the Pharmaceutical Committee, making "investigations in respect of the drugs and appliances ordered by 65 practitioners during the period 12th to 30th April, 1914." I am then informed that, while for this period " the average cost of the prescriptions issued by all the practitioners on the panel was 9.7 pence," in my "individual case the average cost per prescription was nearly 1s. 1d." I should like to dilate on the futility of an inquiry of this sort, in which no account is taken of the length of period for which medicine is supplied by each prescription; as a number of weekly prescriptions, costing, say, an average of $2 s$, are a less demand on the drug fund than a correspondingly larger number of two-day prescriptions covering the same periods. and costing an average of $9 d$. I should also like to. know whether several prescriptions on one form, such as I am habitually writing, are counted as one or as many. In either case, by re-writing the prescriptions on new but more forms, and breaking them up, it would be perfectly easy, without at all altering the total amount prescribed, to reduce one's "average"-calculated in this absurd wayto almost any figure one wished.

But I am writing on a far more important matter which deeply concerns the other 64 practitioners alluded to. The Panel and Pharmaceutical Committees claim in this notice that they are carrying out the provisions of Article 40 of the Regulations of 1913. Now this article only empowers an "investigation" ......" where it appears to the Panel Committee ...... that the cost of the supply of ...... the drugs or appliances ordered for insured persons ..... is in excess of what may reasonably be necessary for the adequate treatment of those persons"-that is to say, it authorises an investigation into prescriptions written for insured persons, to be made while those persons are taking those prescriptions. It cannot, therefore, apply to any inquiry into a number of prescriptions six months or more after the persons prescribed for have ceased to be under that treatment! Even if the wording of the article were not plain (which it is), common sensewhich does not appear to be a strong point of the cormmittees concerned-should show the impossibility of determining "what may reasonably be necessary for the adequate treatment" of anyone except when that person's ailment, symptoms, and idiosyncrasies (which, pace these Pharmaceutical and Panel Committees, even panel patients are human enough to have) can be actually examined and reported upon.

Another important point is that the Panel Committee are only empowered to "make a report to the (Insurance) Committee," on which alone the latter can act, "after hearing any practitioner concerned." Now no practitioner can be "heard" unless he voluntarily goes to the inquiry, and, when there, speaks. The Act and Regulations give the Panel Committee no power to compel him either to attend or to speak if he does attend, and yet no power to do anything without "hearing" him. I therefore advise my 64 brethren to reply, as I have done, that the "investigation" authorised by Article 40 is one to be undertaken during the treatment of the persons concerned, that this inquiry is therefore illegal, and that they must decline to give the Panel Committee the assistance of their presence, and will hold them legally responsible for any consequences that may ensue from their continuing to so conduct it. For my part, I welcome the "unsolicited testimonial" thus given me to the thoroughness of my treatment of my insured patients, for whom I, at all events, practically never order anything not in the British Pharmacopoeia.

I am, Sir, yours faithfully,

Henry BazeTt, M.A. Oxon., M.R.C.S. Eng., L.R.C.P. Lond,

St. Mary's-terrace, Paddington, Nov. 9th, 1914. 